\title{
O mexilhão Perna perna (Linnaeus) (Bivalvia, Mytilidae) em cultivo na Armação do Itapocoroy, Santa Catarina, Brasil
}

\author{
Adriano W. C. Marenzi \& Joaquim O. Branco \\ Centro de Maricultura, Universidade do Vale do Itajaí. Avenida Itacolomy 228. 88385-000 Armação, Penha, Santa \\ Catarina, Brasil. E-mail: marenzi@univali.br
}

\begin{abstract}
The mussel Perna perna (Linnaeus) (Bivalvia, Mytilidae) in culture at the Armação of the Itapocoroy, Santa Catarina, Brazil. To verify the viability of the culture of the mussel, P. perna (Linnaeus, 1758), in the south of Brazil, two experiences had been executed in the Armação do Itapocoroy. The averages of the salinity, temperature and the oxygen had shown ideals for this species and the macronutrients are inside of the natural levels for coast areas, not indicate organic pollution in the place. The average growth was of 0,58 cm/month and the increase of the weight was of $2.57 \mathrm{~g} /$ month. Curves of growth and fattening had been elaborated having for result the greater biological production after 6.7 months of culture. The survival after eight months was $79.2 \%$ and the most raised values of the gonad-somatic index were detected in the spring.
\end{abstract}

KEY WORDS. Crustacea, culture of mussel, curve of growth.

RESUMO. Para verificar a viabilidade do cultivo do mexilhão, $P$. perna (Linnaeus, 1758) no sul do Brasil, duas experiências foram executadas na Armação de Itapocoroy. Das variáveis físicas e químicas foram analisadas a salinidade, temperatura e o oxigênio, que se mostraram ideais para esta espécie e, os macronutrientes também dentro dos níveis esperados para a região, não indicando poluição orgânica no local. $O$ crescimento médio foi de $0,58 \mathrm{~cm} /$ mês e o aumento do peso foi de 2,57 g/mês. Curvas de crescimento e engordas foram elaboradas tendo como base a produção biológica após 6,7 meses de cultivo. A sobrevivência após oito meses foi de 79,2\% e os valores os mais elevados do índice gônodo-somático foram detectados na primavera.

PALAVRAS CHAVES. Crustacea, cultivo de mexilhão, curva de crescimento.

A mitilicultura ou cultivo de mexilhões em corda, no litoral catarinense é desenvolvida em sistema intensivo de monocultivo semi-integral, não demandando investimentos em larvicultura e alimentação, utilizando áreas de elevada produtividade. Essa modalidade de cultivo apresenta excelente taxa de conversão alimentar e com rendimento por unidade de superfície superior ao de qualquer outra cultura em ambiente natural (MANSON 1976, ANDRÉu 1976).

A elevada produtividade da mitilicultura, acrescida da possibilidade de adequar as técnicas de cultivo às características ambientais e sociais de cada local (Morales 1983), contribuíram para o sucesso da atividade, alcançando em 1998 uma produção mundial de 1.688,855 toneladas de mexilhões (FAO 1998).

No Brasil, a partir da década de 90, ocorreu um incremento abrupto no cultivo do mexilhão Perna perna (Linnaeus, 1758), atingindo uma produção na ordem de 12.500 toneladas em 2000, elevando o país ao segundo lugar na América-Latina. Com destaque para o Estado de Santa Catarina, que devido as condições sociais e ambientais favoráveis, responde por aproximadamente $95 \%$ da produção nacional, tendo o Município de Penha como o maior produtor nacional com 3.500 toneladas (Carvalho Filho 2001).

Revista Brasileira de Zoologia 22 (2): 394-399, junho 2005
Este trabalho tem como objetivo caracterizar o desenvolvimento de Perna perna em função de variáveis ambientais, macronutrientes, índice de condição e a sobrevivência em um cultivo comercial, na Armação do Itapocoroy, Penha, Santa Catarina.

\section{MATERIAL E MÉTODOS}

As amostragens foram realizadas bimestralmente entre dezembro de 1996 e novembro de 1997, na Armação do Itapocoroy $\left(26^{\circ} 58^{\prime} \mathrm{S}\right.$ e $\left.48^{\circ} 35^{\prime} \mathrm{W}\right)$. A área encontra-se geograficamente protegida dos ventos mais intensos do quadrante sul, e exposta aos do quadrante norte de menor intensidade, o que reflete na constituição areno-lodosa do sedimento de fundo, característico de área de moderada ação hidrodinâmica.

$\mathrm{Na}$ caracterização física e química da água no local do cultivo, foram registradas bimestralmente, a temperatura, salinidade, transparência da água com disco de Secchi, bem como, coletadas amostras bimestrais da água para determinar a concentração de oxigênio dissolvido utilizando o método de Winkler, e os teores dos macronutrientes (fosfato, nitrito, nitrato e amônio) por espectrofotometria, além do seston (total, orgânico e inorgânico). 
A quantidade de seston foi obtida filtrando-se um volume determinado de água do local (filtro Whatman $n^{\circ} 4$ pré-pesado), secando o material em estufa a $40^{\circ} \mathrm{C}$ até atingir peso constante e, para separar a fração orgânica da inorgânica do seston, esta amostra foi pesada novamente após ser calcinada em mufla por uma hora a $450^{\circ} \mathrm{C}$ para eliminação da parte orgânica.

Para iniciar cada experimento, foram coletados mexilhões jovens ou "sementes" com 2,5 a 3,5 cm de comprimento em um banco natural, próximo ao local de cultivo e, aleatoriamente, foram amostrados 300 exemplares para determinar o comprimento inicial total em centímetros (Lt) e peso inicial em grama (Wt).

Em seguida, foram utilizadas redes tubulares de algodão com $1 \mathrm{~m}$ de comprimento, diâmetro de aproximadamente 10 cm e abertura da malha de um centímetro entre-nós, sendo, esta rede de algodão, colocada dentro de uma rede de nylon também tubular e com $3 \mathrm{~cm}$ entre-nós e, o interior deste conjunto foi preenchido com os mexilhões.

Assim, foram distribuídos 500 indivíduos de forma homogênea em cada rede, fixada uma etiqueta para controle, sendo rapidamente levadas para o mar, e amarrada por uma extremidade em uma corda suspensa na superfície por flutuantes denominada "long-line", distantes $50 \mathrm{~cm}$ uma das outras.

Após dez dias de imersão, a rede de algodão rompeu-se, estando os mexilhões fixados entre si, para gradativamente, ultrapassarem a rede de nylon ficando expostos ao meio externo. Com a utilização desta técnica de encordoamento das sementes seguiu-se a rotina dos maricultores da região, procurando avaliar o desenvolvimento dos mexilhões e seu melhor rendimento para a comercialização.

Foram desenvolvidos dois experimentos, um bimestral e outro contínuo.

Bimestral: nesse experimento procurou-se avaliar o crescimento dos mexilhões a cada bimestre. Em dezembro de 1996, duas redes foram imersas e mantidas no mar por dois meses, sendo substituídas por outras duas com o mesmo número e tamanho dos mariscos e retiradas no bimestre seguinte, esse processo foi repetido por seis vezes durante o ano. A ANOVA (SOKAL \& Rohlf 1969), foi utilizada para verificar a existência de diferenças significativas nas taxas médias de crescimento entre os bimestres. O contraste das médias, através do teste de TukeyKramer, foi aplicado na ocorrência de diferenças significativas para indicar a possível fonte variação.

Contínuo: esse experimento foi montado para avaliar o crescimento interrupto dos mexilhões até alcançarem o tamanho de comercialização. Assim, em abril de 1997 foram imersas simultaneamente 12 redes, sendo retiradas a cada bimestre duas e realizado a biometria dos exemplares. A opção desta data para iniciar o experimento, justifica-se pelo maior recrutamento da espécie ocorrer no início do verão, e após quatro meses, os mexilhões encontram-se, em média com 3,0 cm de comprimento total, sendo o tamanho ideal para o início de um cultivo. Já que os mexilhões são oriundos de um único local e tamanho semelhante, sugerindo um mesmo pulso de recruta- mento, foi possível estimar a curva de crescimento em comprimento total (BERTALANFFy 1938), após testada a validade da expressão de von Bertalanffy pela a aplicação da transformação de Ford-Walford (WALFORD 1946).

Utilizando o modelo de HosoKawa (1986) neste experimento, foi possível avaliar o incremento de peso dos mexilhões e determinar o ponto de tangência máxima da curva de engorda ou término da maturidade.

Em ambos os experimentos, no processamento das redes e biometria dos mexilhões, foi adotado mesmo o procedimento, iniciando pela separação dos organismos associados e contados todos os mexilhões presentes nas rede de cultivo. Na determinação da sobrevivência foi diminuído o número inicial de sementes do número de exemplares em cada período de imersão, sendo também analisado as conchas dos mortos, procurando identificar o possível predador.

Para determinar o desenvolvimento, em cada amostragem realizada nos experimentos, separou-se aleatoriamente 300 exemplares de cada rede, sendo registrado o comprimento total e o peso total. Além, de outra subamostra com 30 mexilhões de cada rede e experimento amostrado, para determinar o Índice de Condição, que indica a quantidade de partes moles ou produto comestível em relação ao espaço da cavidade da concha, utilizando o peso seco das partes moles dividido pelo volume inter-valvar (BAIRD 1966). De acordo com esse autor, mexilhões com índice inferior a "seis" são inadequados para a comercialização, e os acima de "dez" considerados ideais para a colheita.

\section{RESULTADOS E DISCUSSÃO}

Em geral, os dados das variáveis ambientais, representam as condições dos experimentos. A temperatura da água de superfície variou em $9,0^{\circ} \mathrm{C}$ dentro do padrão sazonal esperado, com uma média mensal máxima de $27,0^{\circ} \mathrm{C}$ entre dezembrojaneiro e mínima de $18,0^{\circ} \mathrm{C}$ em junho- julho (Tab. I).

A temperatura interfere diretamente no desenvolvimento dos mexilhões, na taxa de crescimento, ciclo sexual e filtração, e indiretamente por conseqüência da energia radiante, fundamental na disponibilidade de alimento por condicionar a produção primária (Loo \& Rosenberg 1983).

Esses autores argumentam que a variação da temperatura também regula os processos fisiológicos por estar correlacionada com os teores de oxigênio dissolvido, sendo a média anual desta variável na Armação do Itapocoroy de $8,7 \mathrm{mg} / \mathrm{l}$, com as menores concentrações $8,54 \mathrm{mg} / \mathrm{l}$ ocorrendo em março e as maiores em setembro $8,99 \mathrm{mg} / \mathrm{l}$, padrão considerado normal para águas neríticas da região sul e sudeste do Brasil (BRANDINI 1989), habitat preferencial desta espécie.

Como na área do experimento não há fonte hídrica continental significativa, a salinidade manteve-se dentro dos índices esperados para a massa de água desta região costeira, com média anual de 30,49\%o, oscilando entre 32,99\%o no verão e 26,71\% no inverno (Tab. I).

Revista Brasileira de Zoologia 22 (2): 394-399, junho 2005 
Tabela I. Valores anuais máximos, mínimos e médios das variáveis ambientais e macronutrientes analisadas, durante o período amostral.

\begin{tabular}{lrrrrr}
\hline \multicolumn{1}{c}{ Variáveis } & $\mathrm{N}$ & Mínimo & Máximo & Média & Desvio padrão \\
\hline Transparência $(\mathrm{m})$ & 24 & 3,00 & 2,00 & 2,40 & 0,51 \\
Temperatura $\left({ }^{\circ} \mathrm{C}\right)$ & 24 & 27,00 & 18,00 & 22,83 & 7,65 \\
Salinidade $(\% o)$ & 24 & 32,92 & 26,71 & 30,49 & 5,14 \\
Oxigênio $(\mathrm{ml} / \mathrm{l})$ & 6 & 8,99 & 8,54 & 8,70 & 0,14 \\
Seston $(\mathrm{g} / \mathrm{l})$ & 6 & 109,33 & 2,32 & 35,53 & 51,10 \\
Fosfato $\left(\mu \mathrm{g}\right.$ at. $\left.\mathrm{PO}_{4} / \mathrm{l}\right)$ & 6 & 0,45 & 0,15 & 0,27 & 0,19 \\
Amônio $\left(\mu \mathrm{g}\right.$ at. $\left.\mathrm{NH}_{4} / \mathrm{l}\right)$ & 6 & 2,23 & 0,15 & 0,87 & 0,98 \\
Nitrito $\left(\mu \mathrm{g}\right.$ at. $\left.\mathrm{NO}_{2} / \mathrm{l}\right)$ & 6 & 0,16 & 0,01 & 0,10 & 0,05 \\
Nitrato $\left(\mu \mathrm{g}\right.$. at. $\left.\mathrm{NO}_{3} / \mathrm{l}\right)$ & 6 & 9,39 & 0,39 & 3,36 & 4,86 \\
\hline
\end{tabular}

Os valores de temperatura e salinidade registrados nos experimentos, reafirmam o potencial da Armação do Itapocoroy um local adequado ao cultivo de P. perna (SAlOMÃo et al. 1980). Essa informação é fundamental na instalação segura de uma maricultura comercial, pois as interações entre temperatura e salinidade regulam o ritmo de filtração e, conseqüentemente, atuam diretamente no de desenvolvimento dos mexilhões (ANDRÉu 1976).

Durante um ciclo anual, a transparência média quinzenal da água de superfície foi de 2,4 m, com as menores visibilidades médias ocorrendo durante o inverno $(1,6 \mathrm{~m})$ e as maiores no verão (3,3 m) (Tab. I). Para Redhouse (1984), as taxas de crescimento dos mexilhões em cultivos são superiores as do habitat natural, essa tendência foi mantida no presente estudo pela disponibilidade de alimento observado em suspensão na água. Embora, as freqüentes oscilações registradas na transparência, não representam os possíveis valores máximos e mínimos que esta variável pode ter atingido, servindo apenas como indicadores da presença constante de material, potencialmente alimentar, na coluna de água.

O seston apresentou flutuações acentuadas ao longo do ano, com menores valores $(2,32 \mathrm{~g} / \mathrm{l})$ no verão e maiores $(109,33 \mathrm{~g} / \mathrm{l})$ no inverno, com média anual de 35,53g/l, sendo, composto por aproximadamente $50,2 \%$ de matéria inorgânica e $49,8 \%$ de matéria orgânica.

Os altos índices de matéria orgânica encontrada no seston local, quando comparadas aos registrados (12\%) no Mar de Waldden (Holanda), na maior região produtora de mexilhões Mytilus edulis (Linnaeus, 1758 (ANDRÉU 1976), indicam uma farta disponibilidade de alimento que, conseqüentemente, propicia o rápido crescimento.

Quanto aos níveis de seston inorgânico composto por partículas minerais suspensas na coluna de água, os dados obtidos não se enquadram nos níveis aceitáveis para a espécie $M$. edulis citados por CeCCHERell \& BARBoni (1983), onde relatam os efeitos prejudiciais da argila na filtração dos mexilhões, comprometendo seu desenvolvimento pela presença de areia na cavidade intervalvar, tornando o produto inapto para o consumo.

Revista Brasileira de Zoologia 22 (2): 394-399, junho 2005
Para a espécie $P$. perna, este valor máximo de seston inorgânico não é identificado, sendo que nestes experimentos não observou-se material arenoso na cavidade inter-valvar dos indivíduos.

$\mathrm{Na}$ instalação de um cultivo de organismos filtradores, é imprescindível identificar os níveis de compostos potencialmente poluentes no meio, visto que a poluição orgânica é o principal fator limitante seleção de áreas para a aqüicultura (BorghetTi et al. 2003).

Os macronutrientes fosfato e nitrito apresentaram valor constante, ao contrário do amônio e nitrato, sendo que este último apresentou teor médio relativamente alto para uma água isenta de aporte da material continental (Tab. I). Os valores máximos dos macronutrientes estão acima dos registrados nas águas oceânicas, e dentro do padrão esperado para regiões neríticas, não indicado a presença de poluição orgânica no local (BAYNe \& Newell 1983).

Especificamente quanto a atividade do cultivo, segundo Bayne \& Newell (1983), os níveis dos macronutrientes detectados permite que os mexilhões realizem de forma plena seus processos fisiológicos e também, possibilita a intensificação da atividade, pelo fato dos valores de nitrato apresentarem proporção adequada em relação aos demais compostos nitrogenados, amônia e nitrito, indicando a ação efetiva de bactérias na mineralização do seston orgânico e disponibilizando nutrientes para o desenvolvimento do fitoplâncton.

Os mexilhões do Experimento Bimestral não apresentaram diferenças significativas de tamanho entre os períodos cultivados $\left(\mathrm{F}_{4-299}=1,601 ; \mathrm{p}>0,05\right)$ (Fig. 1). Ao longo do ano, os melhores incrementos em comprimento foram registrados entre outubro-novembro, com um crescimento médio de até 2,2 $\mathrm{cm}$, a partir das sementes de 3,0 cm, atingindo em média 5,2 $\mathrm{cm}$ no bimestre, enquanto que, nos meses de fevereiro-março, alcançou 4,2 cm no bimestre, seguido de dezembro- janeiro com 4,1 cm. O menor desenvolvimento, como esperado, ocorreu no inverno (agosto-setembro) com um incremento médio de $0,9 \mathrm{~cm}$ ao tamanho inicial.

Provavelmente, a disponibilidade de micro algas duran- 

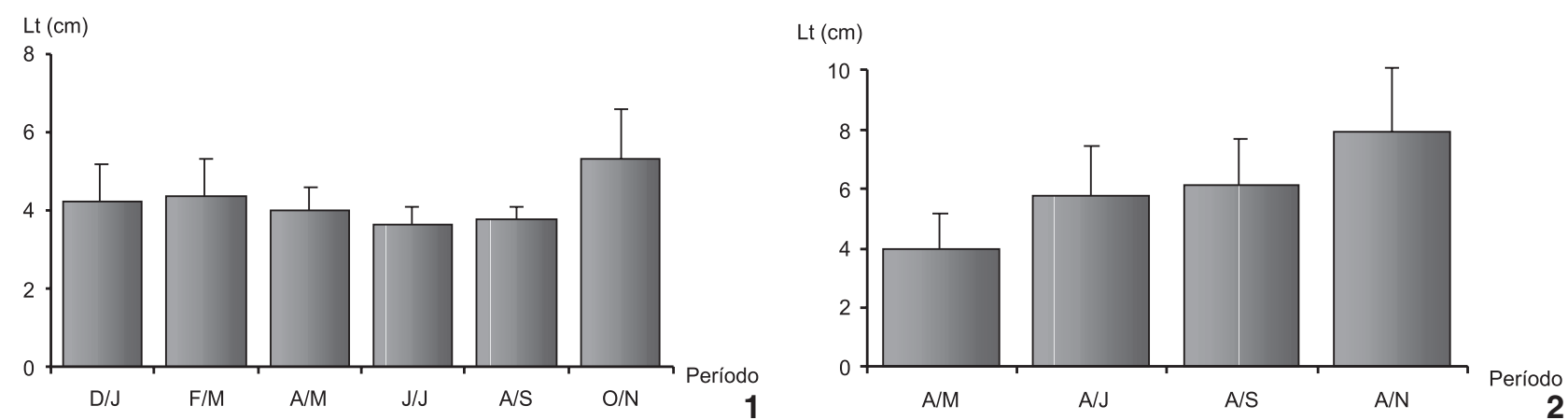

Figuras 1-2. Tamanho médio dos mexilhões e desvio padrão dos experimentos (1) bimestral e (2) contínuo.

te os meses de primavera tenham contribuído para os melhores incrementos de tamanho dos mexilhões. Embora, sejam contraditórias as vantagens sobre uma alimentação fitoplânctonica em relação a uma detritívora (SALAYA 1973).

No Experimento Contínuo, os mexilhões apresentaram crescimento constante ao longo dos bimestres de imersão, atingindo em média $7,7 \mathrm{~cm}$ de comprimento, com um incremento médio mensal de $0,58 \mathrm{~cm}$ (Fig. 2). Apesar de razoável, a taxa mensal de desenvolvimento do $P$. perna na Armação do Itapocoroy, ficou abaixo de $0,7 \mathrm{~cm} /$ mês obtido nos mexilhões cultivados na Espanha (ANDRÉu 1976). Em regiões de clima frio, como na Rússia, apesar dos mexilhões (M. edulis) demorarem até quatro anos para atingir $5,0 \mathrm{~cm}$, a mitilicultura, ainda é considerada uma boa atividade econômica (SUKHOTIN \& KULAKOwSKI 1992).

A curva de crescimento obtida para os mexilhões do Experimento Contínuo, mostra que a partir de $7,0 \mathrm{~cm}$ e uma idade em torno 7,3 meses, $P$. perna tende a reduzir seu incremento de comprimento (Fig. 3).

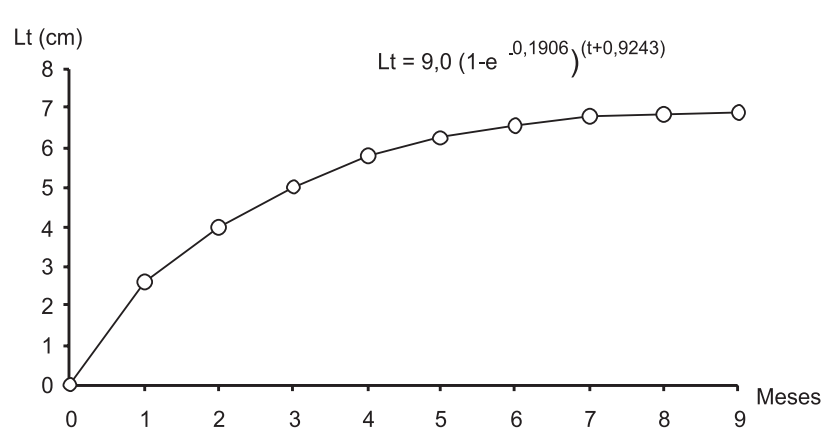

Figura 3. Curva de crescimento em comprimento nos mexilhões do experimento contínuo.

Os mexilhões do Experimento Bimestral, apresentaram em outubro-novembro a maior taxa de engorda, com um acréscimo médio de 3,7 g ao inicial (3,2 g), em média, cada mexilhão estava com 6,9 g (Fig. 4). Em contraste com o bimestre anterior (agos- to-setembro), quando foi registrada uma taxa média de 1,1g. O incremento médio em peso no Experimento Contínuo, esteve em torno de $2,57 \mathrm{~g} / \mathrm{mês}$ por indivíduo, atingindo em média no final dos oito meses de cultivo $23,8 \mathrm{~g}$, acrescentando em média, a cada mexilhão, 20,6 g ao peso inicial de 3,3 g (Fig. 5).

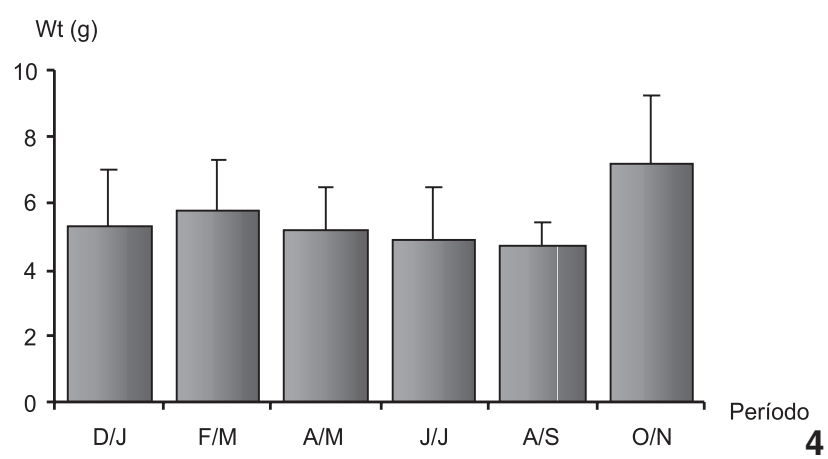

Wt (g)

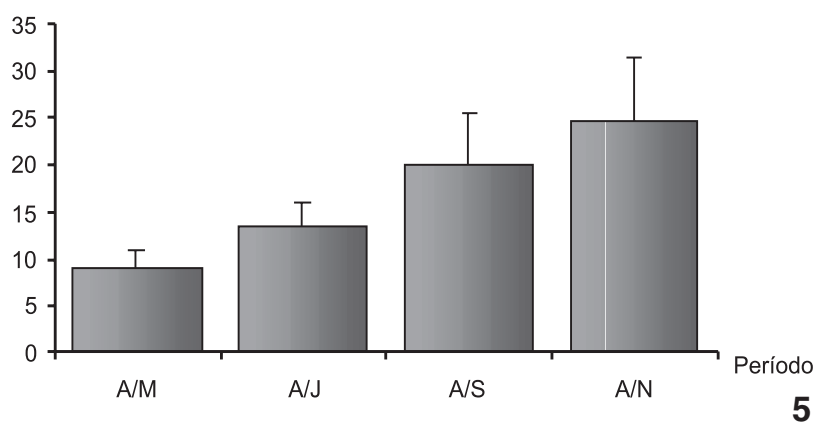

Figuras 4-5. Peso médio dos mexilhões e desvio padrão dos experimentos (4) bimestral e (5) contínuo.

Com os dados do Experimento Contínuo, determinou-se a curva do acréscimo de peso ou engorda, detectando a máxima produção biológica aos 6,7 meses de cultivo, onde os exemplares apresentaram em torno de 21,9g (Fig. 6). Assim, a máxima 


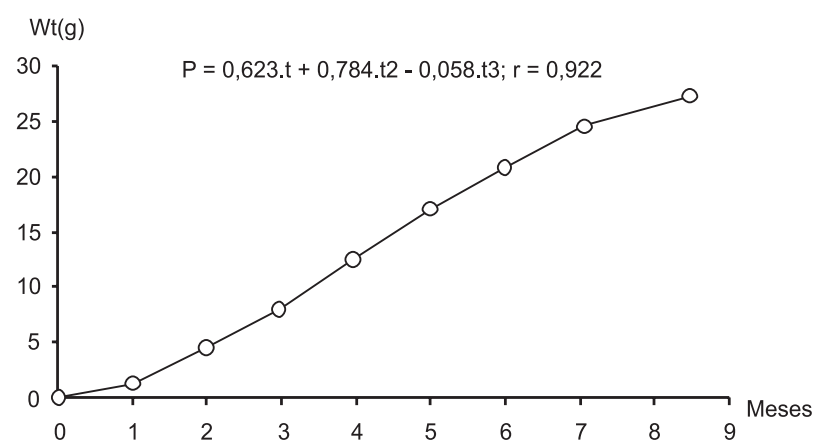

Figura 6. Curva de engorda em peso dos mexilhões do experimento contínuo.

produção biológica pode ser alcançada com $6,9 \mathrm{~cm}$ de comprimento. Após esse período, reduz o ritmo de crescimento e assimilação com a senilidade, havendo maior alocação de energia na manutenção do metabolismo (ROSENBERG \& LAO 1983).

Determinar a máxima produção biológica é fundamental em experimentos que visam estabelecer o tamanho adequado de comercialização dos mexilhões, apesar dos maiores exemplares despertarem o interesse dos consumidores, sua permanência na maricultura é desvantajosa, principalmente pela elevada mortalidade, ação de parasita, incrustações e a redução na taxa de crescimento (BAIRD 1966).

Em geral, todo a área do manto dos mexilhões pode formar gametas, o que contribui no peso da porção comestível. Assim, a variação da quantidade de partes moles, pode estar associada à fisiologia dos organismos, determinando a formação ou liberação de material reprodutivo, contribuindo na comercialização e consumo dos mexilhões.

A avaliação do índice de condição é fundamental para determinar a melhor época de colheita e venda do produto. Os resultados dos experimentos Bimestral e Contínuo indicam que a partir de junho-julho ocorreu um incremento gradual na condição dos mexilhões até alcançar os maiores valores em novembro, indicando ser o período ideal para comercialização do produto na Armação do Itapocoroy (Fig. 7).

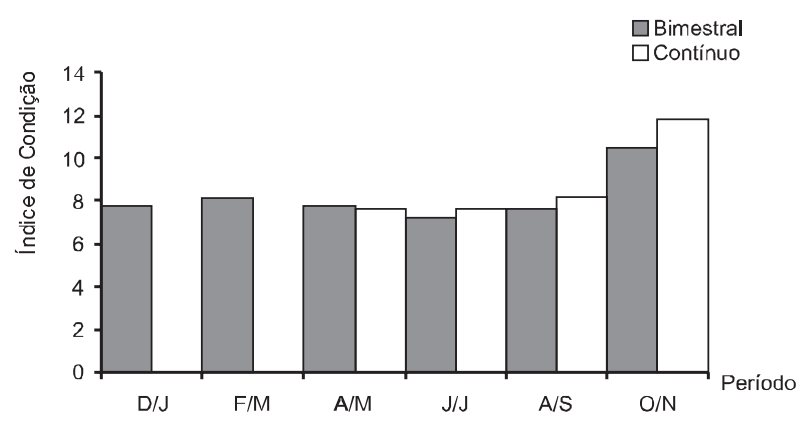

Figura 7. Valores bimestrais do índice de condição, nos experimentos bimestral e contínuo.

Revista Brasileira de Zoologia 22 (2): 394-399, junho 2005
A determinação do tamanho comercial é uma decisão complexa, por divergir das características culturais e dos interesses econômicos, mas deve prevalecer às questões nutricionais e biológicas.

Para Morales (1983), a temperatura é o principal fator na liberação de gametas em mitílideos; porém $P$. perna é um mexilhão tropical, onde as variações sazonais são pouco delimitadas, sendo a atividade gametogênica o resultado da das interações ambientais (UmiJ 1958, LunETTA 1968, Baird 1966). Enquanto que, para MANson (1976), a temperatura pode interferir no índice de condição de $M$. edulis nas regiões temperada, onde a oferta de alimento está relacionada à época do ano. Assim, o incremento de biomassa indica a disponibilidade de alimento primordial no desenvolvimento gônodo-somático dos mexilhões (СHONCHENCHOB 1980). Essa tendência foi registrada no cultivo da Armação do Itapocoroy, com as maiores concentrações de fitoplâncton ocorrendo durante os meses de primavera (RörING et al. 1998).

A maior taxa de sobrevivência dos mexilhões no Experimento Bimestral, ocorreu entre outubro-novembro $(94,8 \%)$ e a menor em dezembro-janeiro (84,4\%), enquanto que na fase inicial do Contínuo, a taxa de sobrevivência esteve em torno de $90,6 \%$, reduzindo para $88,6 \%$ no quarto mês, atingindo no sexto a $80 \%$ e após oito meses, a sobrevivência ficou em $79,2 \%$ (Fig. 8). A maior mortalidade registrada em agosto-setembro, no Experimento Contínuo, pode ser atribuída à ação das ondas e ventos que atingem diretamente a área de cultivo nessa época (RöRIng et al. 1998), portanto, é o período critico para os maricultores da Armação do Itapocoroy.

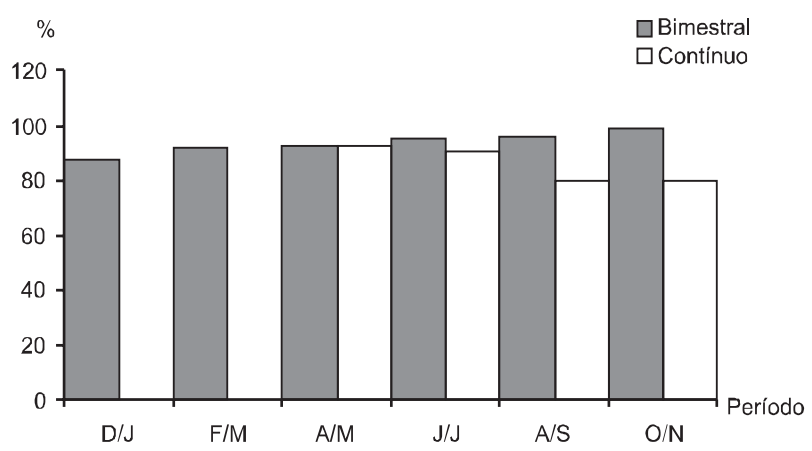

Figura 8. Porcentagem de sobreviventes dos mexilhões, nos experimentos bimestral e contínuo.

O peso e o volume excessivo de mexilhões nas redes podem ter contribuído para a mortalidade de $21 \%$ obtida ao final do Experimento Contínuo (Сноnchenchoв et al. 1980, MatTsson \& LiNDEN 1983). Entretanto, a competição intra-específica pode causar a perda de juvenis, mas é considerada desprezível na biomassa final do produto (DARE \& DAVIS 1975).

Ao analisar as conchas de mexilhões mortos, principalmente os jovens apresentavam a borda posterior fragmentada, 
indicado a ação dos crustáceos decápodes (UROSA 1972, SEED 1976).

Nesse trabalho foram observados alguns fatores como a densidade ideal com poucas redes e utilizado somente o primeiro metro da coluna de água, onde o desenvolvimento é maior (Rosenberg \& Loo 1983, Pineda \& Aguado 1980). Esses cuidados, associados às características ambientais da Armação do Itapocoroy, reafirmam suas potencialidades, sendo recomendado um período de oito meses de cultivo, onde os exemplares com 7,0 cm de comprimento total devem ser colhidos no final da primavera com o melhor rendimento de partes moles em relação ao tamanho da concha.

\section{REFERÊNCIAS BIBLIOGRAFICAS}

ANDréu, B. 1976. El cultivo del mejillon en Europa. Anais da Academia Brasileira de Ciências, Rio de Janeiro, 45 (Supl.): 1-32.

BAIRD, R.H. 1966. Factors affecting the growth and condition of mussels (Mytilus edulis L.). Fisheries and Food Fishery Investigations Series, London, 2: 1-52.

Bayne, B.C. \& R.C. Newell. 1983. Physiological energetics of marine mollusks, p. 407-515. In: S.S.M. SALEuddin \& K.M. WiLbur (Eds). The mollusca physiology. New York, Academic Press, 550p.

BERTALANFFY, L. VON. 1938. A quantitative theory of organic growth. Humman Biology, Detroit, 10 (2): 181-213.

Borghetti, N.R.; A. Ostrensky \& J.R. BorghetTI. 2003. Aqüicultura: uma visão sobre a produção de organismos aquáticos no Brasil e no Mundo. Curitiba, 128p.

Brandini, F.P. 1989. Hydrography and characteristics of the phytoplankton in shelf and oceanic water off southeastern Brazil during winter (july/august,1982) and summer (february/ march,1984). Hydrobiologia, Brussels, 196: 111-148.

CeCCherelli, V.U. \& A. BARBon. 1983. Growth, survival and yield of Mytilus galloprovincialis Lamk. on fixed suspended culture in a bay of the Po river delta. Aquaculture, Arden, 34: 101-114.

Сhoncheunchoв, P. 1980. Handing culture of the green mussel (Mytilus smarangdinus (Chemnatz) in Thailand. Manila, ICLARM Ed., 102p.

DARE, P.J. \& G. DAVIES. 1975. Experimental suspended culture of mussels (Mytilus edulis L.) in Wales using spat transplanted from a distant settlement ground. Aquaculture, Arden, 6: 257-274.

FAO. 1998. Aquaculture Report. Rome, Fisheries Department, $125 \mathrm{p}$.

Hosokawa, R.T. 1986. Manejo e Economia de Florestas. Curitiba, FAO, 125p.

LunETTA, J.E. 1968. Fisiologia da reprodução dos mexilhões (Molusca-Lamellibranchia). Boletins Faculdade de Filosofia Ciências e Letras da Universidade de São Paulo, São Paulo, 26: 33-111.

Loo, L.O. \& R. Rosenberg. 1983. Mytilus edulis culture: growth and production in Western Sweden. Aquaculture. Arden, 35: 137-150.

Carvalho Filho, J. 2001. Panorama da malacocultura brasileira.
Panorama da Aqüicultura. São Paulo, 64: 25-31.

Manson, J. 1976. Marine mussels: their ecology and physiology, p. 25-50. In: B.L. BAYNE (Ed.). Marine mussels cultivation. Cambridge, Cambridge University Press, 550p.

Mattsson, J. \& O. Linden. 1983. Benthic macrofauna succession under mussels Mytilus edulis L. (bivalvia) cultured on hanging long-lines. SARSIA, Bergen, 68: 97-102.

Morales, J.C. 1983. Acuicultura Marina Animal. Madri, MundiPrensa Ed., 423p.

Pineda, J. \& A. Aguado. 1980. Variacion mensual de la composicion quimica del mejillon Perna perna (L.) cultivado y las condiciones ambientales en la Bahia del Guamache, Isla de Magarita, Venezuela. Boletim Instituto Oceanográfico, Caracas, 29 (2): 305-311.

Redhouse, P.G. 1984. Food resource, gametogenesis and growth of Mytilus edulis an the shore and in suspended culture: Killary Harbour, Ireland.Great Britain. Jornal of Marine Biology, London, 64: 513-529.

Röring, L.R.; S.C.P. Guimarães; D.O. Lugli; L.A.O. ProençA; G.C. Manzoni \& A.W.C. Marenzi. 1998. Monitorização de microalgas planctônicas potencialmente tóxicas na área de maricultura da Enseada da Armação do Itapocoroy, Penha, SC. Notas Técnicas da FACIMAR, Itajaí, 2: 71-79.

Rosenberg, R. \& L. Loo. 1983. Energy-Flow in a Mytilus edulis culture in Western Swedem. Aquaculture, Arden, 35: 151-161.

SALAYA, J.J. 1973. Estudio sobre la biologia pesqueira y cultivo del mejillon Perna perna (L.), en Venezuela. Caracas, Ministério de Agricultura y Cria, Oficina Nacional de Pesca, Informe Técnico numero 62, 49p.

SAlomão, L.C.; A.R.M. Magalhães \& J.E. LunetTa. 1980. Influencia da salinidade na sobrevivencia de Perna perna (Mollusca: Bivalvia). Boletim de Fisiologia Animal Universidade de São Paulo, São Paulo, 4: 143-152.

SEED, R. 1976. Marine mussels: their ecology and physiology, p. 13-66. In: K.M.Wilbur \& C.M. Yonge (Eds). Physiology of mollusks. New York, Academic Press, vol. 1, 226p.

SOKAL, R.R. \& F.J. RoHLF. 1969. Biometry, the principles and practies of statistics in biological research. San Francisco, W.H. Freeman, 776p.

Sukhotin, A.A. \& E.E.G. Kulakowski. 1992. Growth and population dynamics in mussels (Mytilus edulis L.) cultured in the White Sea. Aquaculture, Arden, 101: 59-73.

UmiJ, S. 1958. Neurosecreçao de Mytilus perna (Molusco-Lamelibranquio). Boletim de Zoologia e Biologia Marinha, São Paulo, 1: 181-254.

Urosa, L.J. 1972. Algunos depredadores del mejillon comestible Perna perna (L.). Boletim do Instituto Oceanográfico da Universidade do Oriente, Caracas, 11 (1): 3-18.

WALFORD, L.A. 1946. A new graphic method of describing the growth of animals. Biological Bulletin Marine Biological Laboratory, Massachusetts, 90 (2): 141-147.

Recebido em 28.X.2003; aceito em 17.V.2005. 